\title{
The teaching content improvement within the hierarchical practical teaching system of accounting profession in independent colleges_-Taking the accounting profession of Jiangcheng College, China University of Geosciences as an example
}

\author{
Hui-Ling CHENG ${ }^{1, a,{ }^{*}}$, Ying-Jie WEN ${ }^{1, b}$, Yu-Jian YAO ${ }^{1, c}$ \\ ${ }^{1}$ Jiangcheng College, China University of Geosciences,No.8 in Xiong Tingbi Street, Jiangxia District, \\ Wuhan City, Hubei Province, China \\ a342395131@qq.com, b402537057@qq.com , 'beichangyao@163.com \\ ${ }^{*}$ Corresponding author
}

Key words: Practical teaching,Hierarchical system, Teaching content improvement.

\begin{abstract}
Practical teaching plays a more and more important role in the process of applied talents training. Taking accounting of Jiangcheng College, China University of Geosciences as an example, this paper expounds the prominent problems in its practical teaching, and puts forward ideas of improving the teaching content within the hierarchical practical teaching system of accounting in independent colleges.

After eight years of development, Jiangcheng College of China University of Geosciences has become a domestic independent college with certain popularity, and its practical teaching system construction of accounting has made certain achievements. However, the most prominent problem in the practical teaching system is that the practical teaching content still cannot fully meet the market demand for multi-level talents. The current training courses of accounting are mainly those popular courses such as the Manual Simulated Training of Accounting, Accounting Computerization Training, Tax Filing Training, and Audit Training. Although these courses have made certain contribution to the cultivation of applied talents and to the development of discipline construction, as the employers ask for more and more diversified and compound applied talents, the imperfectness of the practical teaching content of accounting practical teaching system has been gradually revealed. Therefore, it is urgent to further clarify the levels of the practical teaching system, and enrich and perfect the practical teaching content.

The hierarchy of the practical teaching system should be con ${ }^{1}$ sidered first, for the collocation and cohesion of these training courses should be based on the requirements of different levels, and different levels and steps should be integrated into a whole. Usually, the practical teaching system of accounting could be divided into three levels: basic skill level, professional skill level and comprehensive training level.
\end{abstract}

\section{The basic skill level}

There is an old saying that great oaks grow from little acorns. This level is quite important, for it decides whether the accounting majors' foundation is strong enough for later professional learning. Combining with the characteristics of weak cultural foundation of independent colleges (the third degree colleges) students, we thus in this level increase appropriate proportion of practical teaching content, focusing on training students' basic operation skills. And the specific arrangement is as follows: through the Introduction to Accounting, the accounting freshmen gain a fully understanding of the accounting major in the first semester. Introduction to Accounting is suggested to be added into

${ }^{1}$ This paper is a phased achievement of the teaching and research project in Hubei, Research on Professional Practical Teaching System on Economic Management Professions in Independent Colleges. (project number: 2012451) 
the practical teaching content, which is conducive to students' general understanding of accounting, intriguing their interests of learning. Then, through Summer Cognitive Internship, the students could learn about the structure of the accounting institutions and accounting system, as well as the basic process of accounting work, thus to have a general knowledge of accounting practice work. At the same time, the Summer Cognitive Internship will also help students to accumulate certain perceptual knowledge for enterprise business process, laying the foundation for the study of basic professional courses in the future.At present, Summer Cognitive Internship is arranged in the summer vacation of the sophomore year, and it is suggested to be arranged in the summer vacation of freshman year, thus laying a foundation for the later basic professional course Principles of Accounting ahead of time. While the practice course, Manual Simulated Training of Accounting, could be arranged as a simultaneous course with Principles of Accounting, set up in the second semester, and the learning process in each section could be equipped with the corresponding practical training content. For example, when the teacher is in the teaching of the source documents, he(she) can organize the students to collect related source documents in daily life, such as the payment slip for purchasing, sales invoices, certificates of deposit and withdrawal slips, and ask the student to check those collected source documents, learning about the format, content, and filling requirements of all kinds of certificates, analyzing commonness and individuality of different kinds of certificates to determine whether the invoices are formal, and whether they could be used as vouchers for keeping accounts. The eight credit hours of practice courses on computer, Basic Accounting Training, could be arranged at the end of Principles of Accounting, the main contents including: basic writing norms of accounting, the filling and checking of source documents, the filling and checking of accounting vouchers, the compilation method of accounting voucher summary sheets, keeping accounts and trial balance, reconciliations and closing the books, preparation methods of bank balance reconciliation sheets, the filling of various kinds of accounting statements. Thus through repeated practice on the computer, the students, on the one hand, consolidate and deepen their understanding of the theoretical knowledge, on the other hand, gain further perceptual knowledge of accounting practice work. In this level, both manual simulation and computer simulation help to consolidate students' foundation.

\section{The professional skill level}

In the professional skills level, we mainly cultivate the students' professional skills through a series of professional practical teaching. At this level, training courses can be divided into three broad categories: ordinary professional skills training courses, comprehensive financial software training courses, and special skills training courses. All these courses could be arranged during the junior year. The first two kinds are required for all the students, while the third courses are advanced courses for the capable students to select as optional courses, which is helpful for us to cultivate students in different levels. In order to combine the accounting theory and practice together, we need to integrate the scattered branch knowledge to be coherent, and through the systematic training of accounting practical teaching system, make the students familiar with the whole process of accounting, and thus gain a further understanding of the main content of accounting. ${ }^{[1]}$ Therefore, we could consider offering such 8-credit-hour courses to be the ordinary professional skills training courses as the Cost Accounting Training and Financial Management Training, Financial Analysis Training, Tax Training, Tax Declaration Training, Audit Training, connected with their corresponding theories. One similarity of these training courses is that they could build a simulated learning environment for students to improve their perceptual knowledge.Take the Financial Management Training for example. The training system offers the financial goals, main product introduction, production capacity, market situation, the corporate governance structure, business risk factors and countermeasures, three years' financial statements of a simulated enterprise, linking together the basic knowledge of cash management, credit management, accounts receivable management, inventory management, comprehensive budget management, investment and financing decisions and capital structure decision in financial management, to make the student to have a comprehensive understanding of the application in the enterprise financial management.Combined with the current course Accounting Computerization Training, comprehensive financial software training courses 
could help the students to learn about the current widely used comprehensive financial softwares such as Kingdee K / 3 and UFIDA U8, which will help the student to enter the work state much faster once they enter the enterprises, for they could be able to work after being familiar with enterprise business a little bit without learning about the financial softwares, greatly saving the enterprise training cost, and improving the students' market competitiveness. At the same time, to form unique characteristics of the accounting in our college, we could also provide some personalized practical courses, such as Bank Accounting Training, Manufacturing Enterprises Export Tax Rebate Training, Consolidated Statements Multimedia Training, and the students can take different courses as their selective courses according to their own future employment direction. The Bank Accounting Training, for example, systematically simulates the real business of commercial banks, such as accepting RMB deposits, issuing short-term, medium-term and long-term loans, dealing with domestic settlement and bills discounting, issuing financial bonds, etc., to make the student fully perceive the bank accounting practical work processes, offering a shortcut for the students who are to enter the banks. While Manufacturing Enterprises Export Tax Rebate Training provides a good platform to learn about the export tax rebates business for those who may work in the foreign trade enterprises in the future, Consolidated Statements Multimedia Training offers a good training base for those who are interested in the consolidated statements work in the group companies. All these courses will certainly make our students more closely to meet the enterprises' demand, thus the students employment rate will increase greatly.

\section{Comprehensive training level}

Comprehensive training level mainly cultivates students' ability to discover, analyze and solve problems and innovation ability with the knowledge learned. It has been pointed out in the Opinions on Vigorously Promoting the Innovation and Enterprise Education in Institutions of Higher Learning and College Students Self-employment issued by the Ministry of Education in 2010: "Effectively involve the innovation and enterprise education into the teaching program of professional education and culture quality education and credit system, to establish a multi-level, three-dimensional innovation and enterprise education curriculum system. Highlight the professional characteristics, and actively promote the reform on talent training mode, teaching content and curriculum system, with entrepreneurial innovation courses combined to professional curriculum system, and the entrepreneurial innovation practice connected to professional practical teaching. ${ }^{[2]}$ Based on this guiding ideology, in this level, we could add some comprehensive practical teaching courses with design and creativity to enrich the teaching content, so this curriculum are more appropriate to be arranged in senior years. Practical training courses like Industrial Sand Table Simulation Matches, the Design of Enterprise Internal Control System are all good choices. Taking Industrial Sand Table Simulation Matches as an example, in this course, six students could be divided into a group playing different management roles. Under the guidance of the teacher, by borrowing and searching a lot of reference materials, the students could make out plans on the future development of the enterprises based on their own judgment on the development trend of the economy and market, and the comparison of their own conditions with competitors' conditions. The implementation of the plan involves a variety of factors such as raw materials, production equipment, marketing, technology innovation, and taking all these factors into consideration, the students of each group could independently manage their own corporation, which would fully exercise the students' comprehensive management abilities such as investment and financing, the production and business operation, marketing, etc.In the process of grouping confrontation, students need not only solid professional skills, but also adequate oral presentations, so the ability of expression is also a key factor deciding whether the group could win or not. In western education system, they attach great importance to the cultivation of students' ability of "statement". For example, in Germany, in their basic education stage, they pay much attention to the students' ability of language expression, and some subjects even give priority to oral exams. And in the stage of higher education, the students are paid more attention to their autonomous learning ability and oral communication ability. The Design of Enterprise Internal Control System might also be set up as a practical training course to exercise 
students' comprehensive ability. The instructors can take the manufacturing industry as an example, dividing it into different stages such as procurement, payment, production, sales and collection based on the enterprise business process and asking the students to design the internal control systems in different stages. In the procurement stage, for instance, the students need to consider how to set up the incompatible positions, how to ensure the separated duties of these positions to reach enterprise internal control goals. Through such design practice in the courses, the students' comprehensive management quality and ability can surely ascend to a new level.Graduation practice and graduation thesis is an important step to make the students apply their knowledge into actual use. For the graduation practice, due to the limited size and number of off-campus practice bases, we still take the dispersed internship strategy. However, due to the fierce competition of accounting, the reluctance of the employers to choose the inexperienced graduating students, and some students' anxiety to find jobs, most of the students' graduation practices are unsatisfactory, which also affects the quality of the graduation thesis. The survey data from To Be Honest: Accounting Education - a Survey Report on the Present Situation Assessment and the Reform Direction of the Accounting Education in 14 National Key Universities show that, for the "internship performance evaluation", college students who chose " very good, good "accounts for only $5.23 \%$ and $26.59 \%$, while "general, poor, very poor" for respectively $39.93 \%, 20.02 \%, 8.23 \%$, with $68.18 \%$ in total. ${ }^{[3]}$ In this level, therefore, one way to enrich the practical teaching content is to encourage the students to carry out multi-channel social practices, such as a variety of social surveys, professional internships, public welfare activities, obligations of teaching activities. All these could help the students to fully understand the society and national conditions, thus on the one hand, improving their comprehensive quality, on the other hand, facilitating their accumulation of graduation thesis materials. The time arrangement for social practice is flexible for the students, and they could arrange the time all by themselves, not necessarily during the period of graduation practice. The school colleges could also create such conditions for the students within their power. For example, our collage arrange students to be a teacher in the countryside each year, which not only exercises the students' communication ability, but also cultivates their persistence to bear hardships, obtaining good practice effect.Another example, Wuchang branch school of Huazhong University of Science and Technology arranges annual summer practice activity in the United States, and eligible students can sign up for it. It has created the conditions for the students to develop international vision and understand foreign cultures, and all the students participated in the activities came back with profound feelings. Encouraging students to take an active part in all kinds of innovative entrepreneurship competitions such as the Challenge Cup Venture Contest, the Accounting Information Skills Contest is another important way to enrich the practical teaching content of this level. In 2012, the accounting major students enrolled in our school in 2008 attended the Sixth National "Ufida Cup" Informationization Contest and won the National Third Group Award as well as the First Group Award of Hubei area, winning not only the honor for our school, but also a good career development for the participating students themselves. Taking part in scientific research projects is also an important way to enrich and improve students' comprehensive ability. In recent years, accounting students from our school has participated in such activities, and achieved gratifying results. Many colleges and universities in the United States, especially the first-class universities, pay much attention to supporting and encouraging students to participate in scientific research work in the process of the talents cultivation, in order to cultivate their innovation ability. For instance, students from Massachusetts Institute of Technology could enter for the UROP project (Undergraduate Rsearch onesearch Opportunities Program), which accept some excellent undergraduates directly to be involved in the scientific research projects, and after they make achievements, they may apply to the Foundation for research funds, also they publish papers, patent, or earn credits. All of these are good references to us.

The multi-level and multi-steps curriculum construction mentioned above could gradually and steadily push forward the practical teaching system of accounting in independent colleges from junior to senior stage, and can realize the hierarchical cultivation to meet different market demands. With the development of science and technology as well as the progress of information, practical teaching methods and means develops with each passing day, and thus the practical teaching content of each 
level need to be constantly improved. The improvement of the practical teaching content should always take the accounting personnel training mode and training objectives as the guidance, keep up with the educational reform pace, innovate practical teaching, strengthen practical education, to reach the ultimate goal of cultivating practical and innovative accounting talents with strong foundation, broad knowledge, high quality, excellent ability and unique personality.

\section{References}

[1] Liu Jianyong, Zhu Xueyi, Zhu Liangfeng. Re Employment-oriented Accounting Practical Teaching System [J]. Journal of Shanxi University of Finance and Economics (higher education). $2010(9)$

[2] Li Dongmei. The Construction of Innovation-oriented Accounting Practical Teaching System [J]. Friends of Accounting. 2011 (1)

[3] Wang Xiankang, Wang Minghua. Research on Accounting Practical Teaching System in Independent Colleges [J]. Chinese Management Informationization. 2009 (4) 